\title{
Application of TOPSIS Method Based on Entropy Weight -Delphi in the Evaluation of Teachers' "double-qualified" Ability
}

\author{
Weixia Wang, He Jun \\ Anhui College of Mechanical and Electrical Technology, Wuhu Anhui_241003, China
}

\begin{abstract}
In order to improve the rationality and fairness of Teachers' "Double-qualified" Ability, the article establishes an evaluation model based on 14 evaluation indexes of teachers' "double-qualified" ability. it adopts Delphi - entropy weight method to weight the evaluation index, and then combines TOPSIS method to evaluate the evaluation object. In the evaluation of TOPSIS method, the traditional TOPSIS weight method was improved, and the entropy weight-delphi method was used to determine the index weight, which was a combination of subjective and objective, making the evaluation system more objective, scientific and reasonable.It not only avoids the subjectivity of decision makers and limitations, but also eliminates the phenomenon of indexes in common impact assessment results and finally applies it to a university teacher "Double division and triple energy " evaluation system, to provide theoretical basis and feasibility analysis for the "double type" teachers team construction.
\end{abstract}

Chinese library classification number: 0224 Document identification code: A

\section{Introduction}

With the transformation and upgrading of China's economic and social development, the higher vocational education has undergone significant reform. The report of the 19th national congress of the communist party of China made it clear that higher vocational education in the new era should deepen the integration of industry and education and cooperation between schools and enterprises, accelerate the construction of first-class universities and disciplines, and realize the connotation development of higher vocational education. The "Double-qualified" teachers are the main force to realize the connotation development of vocational education, the fundamental guarantee to improve the quality of talent training, and the important expression of the core competitiveness of vocational colleges. The concept of "Double-qualified" teachers was put forward in the 1990s to embody the characteristics of vocational education. The original "double-qualified" teacher was defined as a teacher with a "double certificate" or "double professional title". In 2019, the state council issued the implementation plan of the national vocational education reform (hereinafter referred to as article 20 of vocational education), The plan clearly points out that the "double-qualified" teachers are those who have both theoretical teaching and practical teaching abilities, applied undergraduate colleges or higher vocational colleges should take multiple measures to build a "double-qualified" teacher team and focus on cultivating teachers' three abilities: First, theoretical teaching ability and vocational practical teaching ability; second, the ability of "feedback feeding" teaching by using the first-line practice results of enterprises; third, applied scientific research and technology development capabilities (referred to as " double-qualified teachers and three-competent teachers"). Constructing a scientific and reasonable evaluation system of "double-qualified teachers and three-competent teachers" is the approach to the management of "double-qualified teachers", as well as the key to promoting the development of higher vocational education and improving the level of school running and the quality of talent training ${ }^{[1]-[2]}$.

In the process of establishing the evaluation system of "double-qualified teachers and three-competent teachers", combining the characteristics of higher vocational education and expert opinions, this paper puts forward 14 evaluation indexes, which are determined from the aspects of enterprise practice, transformation of scientific and technological research and development achievements, vocational skill level identification, advanced training, etc., focusing on teaching (Table 1), Moreover, entropy weight and Delphi method were used to give weight to the evaluation indicators, and then combined with TOPSIS method to evaluate teachers' " double-qualified teachers and three-competent teachers " [3]-[4]. This method can play a guiding role in building an innovative and "double-qualified teachers and three-competent teachers " teaching staff.

Table 1: The evaluation indexes of teachers

\begin{tabular}{|l|}
\hline \multicolumn{1}{|c|}{ Evaluation indexes } \\
\hline 1.The teacher's ethics strengthen \\
\hline 2. The teaching situation \\
\hline 3.The teaching effect \\
\hline
\end{tabular}

\footnotetext{
* Corresponding author: Wang Weixia 0125000240@ahcme.edu.cn.
} 


\begin{tabular}{|l|}
\hline 4.The research results \\
\hline 5. Construction of teaching material \\
\hline 6. To guide the contest \\
\hline 7. Research papers \\
\hline 8. Scientific research project \\
\hline 9. Scientific research project \\
\hline 10. The patent certificate \\
\hline 11. Promotion of results \\
\hline 12. Promotion of results \\
\hline 13. Enterprise training \\
\hline 14. Other training \\
\hline
\end{tabular}

\section{A TOPSIS evaluation model with Delphi- entropy weights [5]-[8]}

TOPSIS method is a common method to solve multi-objective decision-making problems. This method is to calculate the Euclidean distance from each evaluation object to the positive and negative ideal solution vectors to obtain the degree of closeness between each object and the ideal solution, and then sort the degree of closeness according to the degree of closeness of the ideal solution, and then obtain the degree of superiority and disadvantage of each object. The value of proximity degree is between 0 and 1 . The closer the value is to 1 , the closer the corresponding evaluation target is to the optimal level. Otherwise, the closer the value is to 0 , the closer the evaluation target is to the worst level.

There are subjective weighting method and objective weighting method to determine the weight of evaluation index. Subjective weighting methods include analytic hierarchy process, fuzzy comprehensive evaluation method, Delphi method, etc. To a large extent, these methods rely on the opinions of decision-making experts, which are largely interfered by human factors and have subjective one-sidedness. Objective weighting methods include principal component analysis (pca), mean square error (mse), entropy weighting, etc. This method weights indicators according to the characteristics of the indicator data, which can reduce the subjective factors in the decision-making process and make the decision-making process more standardized and scientific. Therefore, this paper adopts Delphi - entropy weight method to weight the evaluation index, and then combines TOPSIS method to evaluate the evaluation object. The specific steps are as follows:

Assume there are $\boldsymbol{m}$ evaluation schemes $A_{i}(i=1,2, \cdots, n)$ and $n$ index $C_{j}(j=1,2, \cdots, m), \quad x_{i j}$ is the index data of evaluation scheme $\boldsymbol{A}_{i}$ under index $\boldsymbol{C}_{j}$.

(1) The evaluation index is transformed into a standardized matrix by linear proportional transformation, i.e:

$$
\begin{aligned}
b_{i j} & \left.=\frac{x_{i j}}{\max _{1 \leq i \leq m} x_{i}}(j=1,2, \cdots n) \quad \text { (Benefit type index }\right) \\
b_{i j} & =\frac{\min _{1 \leq i \leq m} x_{i}}{x_{i j}}(j=1,2, \cdots n) \quad \text { (Cost type index) }
\end{aligned}
$$

(2) Use Delphi - entropy weight method to determine the weight of evaluation index. Delphi method is a subjective evaluation method of expert opinions. It can reduce the one-sidedness caused by experts' personal preference, reflect different opinions among experts, and make up for the irrationality brought by objective evaluation. The specific calculation steps are as follows:

Assume the set of experts being judged $H=\left\{h_{1}, h_{2}, \cdots h_{m}\right\}$, the weight distribution opinion of $n$ evaluation indicators is given as $A_{i}=\left\{a_{i, 1}, a_{i, 2}, \cdots a_{i, n}\right\}$, satisfying $\sum_{j=1}^{n} a_{i, j}=1$, calculate the weight of each evaluation index under the condition that the expert opinion is consistent:

$$
w_{j}^{(1)}=\frac{1}{m} \sum_{i=1}^{m} a_{i, j}(j=1,2, \cdots n)
$$

Entropy weight method is an objective weighting method to determine the weight of each evaluation index according to the information contained in the index. According to the definition of entropy, the entropy of $\mathrm{m}$ evaluation schemes and $\mathrm{n}$ evaluation indexes is:

$$
H_{j}=-\left(\sum_{i=1}^{m} f_{i j} \ln f_{i j}\right) / \ln m .
$$

Among them

$$
f_{i j}=b_{i j} / \sum_{i=1}^{m} b_{i j}
$$

$$
\text { When } f_{i j}=0, f_{i j}=\left(1+b_{i j}\right) / \sum_{i=1}^{m}\left(1+b_{i j}\right) \text {. }
$$

The entropy weight of the evaluation index is calculated as: $\quad w_{j}^{(2)}=\left(1-H_{j}\right) /\left(m-\sum_{j=1}^{n} H_{j}\right) ; \sum_{i=1}^{n} w_{j}^{(1)}=1$. (7)

This paper combines entropy weight and Delphi method, using linear combination $w_{j}=0.6 w^{(1)}{ }_{j}+0.4 w^{(2)}{ }_{j}$ To determine the weights.

(3) Construct the weighted norm evaluation matrix $Z=\left(z_{i j}\right)_{n \times m}$, among them,

$$
z_{i j}=w_{j} b_{i j},(i=1,2, \cdots m ; j=1,2,3, \cdots, n)
$$

(8) $w_{j}(j=1,2,3, \cdots, n)$ is the weight of the indicator.

(4) Construct the positive ideal solution

$S^{+}=\left(z_{1}^{+}, z_{2}^{+}, z_{3}^{+}, \cdots, z_{m}^{+}\right)$and the negative ideal solution $S^{-}=\left(z_{1}^{-}, z_{2}^{-}, z_{3}^{-}, \cdots, z_{m}^{-}\right)$, among them:

$$
z_{j}^{+}=\max _{1 \leq i \leq m}\left(z_{i j}\right), \quad z_{j}^{-}=\min _{1 \leq i \leq m}\left(z_{i j}\right)(j=1,2, \cdots, m)
$$

(5) Calculate the EUCLIDEAN distance from each evaluation scheme to the positive and negative ideal solutions:

$$
\begin{aligned}
& \boldsymbol{d}_{i}^{+}=\sqrt{\sum_{j=1}^{m}\left(z_{i j}-z_{j}^{+}\right)^{2}}, \\
& \boldsymbol{d}_{i}^{-}=\sqrt{\sum_{j=1}^{m}\left(z_{i j}-z_{j}^{-}\right)^{2}} .
\end{aligned}
$$

(6) The relative closeness of each evaluation scheme to the positive ideal solution is calculated $C_{i}^{+}$, among them

$$
C_{i}^{+}=\frac{d_{i}^{-}}{d_{i}^{+}+d_{i}^{-}} \quad(i=1,2,3, \cdots, m)
$$




\section{Case analysis [9]-[10]}

In this paper, 12 teachers in a university were selected for the "double-teacher, three-ability" evaluation (see figure 1 for evaluation indicators). The scores of 1-14 evaluation indicators corresponding to each teacher are shown in table 2:
According to the Delphi- entropy weighted TOPSIS evaluation model in 1, the solution is as follows: According to the Delphi- entropy weighted TOPSIS evaluation model in 1, the solution is as follows:

(1) The evaluation index can be transformed into a standardized matrix $\mathrm{R}$ by linear proportional transformation.

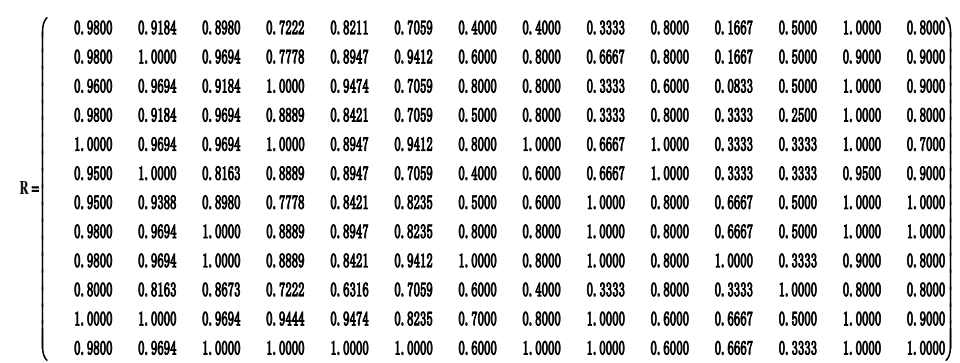

(2) Use Delphi - entropy weight method to determine the weight of evaluation index Eight experts were organized to calculate the subjective weight vector based on knowledge and experience:

$$
\mathrm{w}^{(\mathbf{1})}=(\mathbf{0 . 0 9 , 0 . 0 8 , 0 . 0 8 , 0 . 0 6 9 , 0 . 0 4 9 , 0 . 0 7 9 , 0 . 0 6 2 , 0 . 0 7 1 , 0 . 0 9 , 0 . 0 8 6 , 0 . 0 6 6 , 0 . 0 6 2 , 0 . 0 6 8 , 0 . 0 4 8})
$$

The objective weight vector of the evaluation index is obtained by entropy weight method as follows:

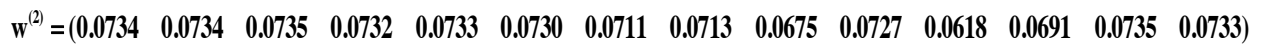

combined weight is:

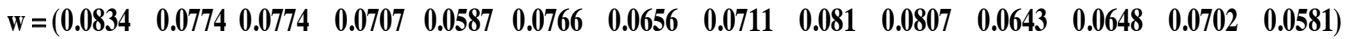

(3) According to $z_{i j}=\boldsymbol{w}_{j} \boldsymbol{b}_{i j}$, the weighted norm evaluation matrix $\mathbf{Z}$ is obtained.

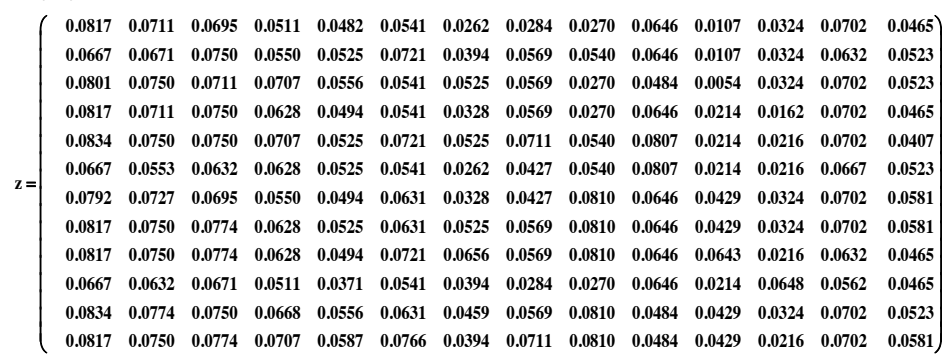

(4) The markov distance from the positive and negative ideal solution and the relative closeness to the ideal solution are shown in table 3 .

According to the ranking of closeness degree, the evaluation ranking of "double teacher and triple energy type" of teachers is as follows: Teacher $9>$ teacher $12>$ teacher $8>$ teacher $11>$ teacher $5>$ teacher $7>$ teacher $2>$ teacher $3>$ teacher $4>$ teacher $6>$ teacher $10>0$ teacher 1 . Among them, teacher 9 has a low score in enterprise practice, but it has a high score in the indicators with high weight (guidance competition, scientific research papers, scientific research awards), so it ranks first. 
Table2: Score sheet of 14 indicators for 12 teachers

\begin{tabular}{|c|c|c|c|c|c|c|c|c|c|c|c|c|c|c|}
\hline indicator & 1 & 2 & 3 & 4 & 5 & 6 & 7 & 8 & 9 & 10 & 11 & 12 & 13 & 14 \\
\hline 1 & 98 & 90 & 88 & 65 & 78 & 60 & 40 & 40 & 20 & 80 & 10 & 40 & 100 & 80 \\
\hline 2 & 80 & 85 & 95 & 70 & 85 & 80 & 60 & 80 & 40 & 80 & 10 & 40 & 90 & 90 \\
\hline 3 & 96 & 95 & 90 & 90 & 90 & 60 & 80 & 80 & 20 & 60 & 5 & 40 & 100 & 90 \\
\hline 4 & 98 & 90 & 95 & 80 & 80 & 60 & 50 & 80 & 20 & 80 & 20 & 80 & 100 & 80 \\
\hline 5 & 100 & 95 & 95 & 90 & 85 & 80 & 80 & 100 & 40 & 100 & 20 & 60 & 100 & 70 \\
\hline 6 & 80 & 70 & 80 & 80 & 85 & 60 & 40 & 60 & 40 & 100 & 20 & 60 & 95 & 90 \\
\hline 7 & 95 & 92 & 88 & 70 & 80 & 70 & 50 & 60 & 60 & 80 & 40 & 40 & 100 & 100 \\
\hline 8 & 98 & 95 & 98 & 80 & 85 & 70 & 80 & 80 & 60 & 80 & 40 & 40 & 100 & 100 \\
\hline 9 & 98 & 95 & 98 & 80 & 80 & 80 & 100 & 80 & 60 & 80 & 60 & 60 & 90 & 80 \\
\hline 10 & 80 & 80 & 85 & 65 & 60 & 60 & 60 & 40 & 20 & 80 & 20 & 20 & 80 & 80 \\
\hline 11 & 100 & 98 & 95 & 85 & 90 & 70 & 70 & 80 & 60 & 60 & 40 & 40 & 100 & 90 \\
\hline 12 & 98 & 95 & 98 & 90 & 95 & 85 & 60 & 100 & 60 & 60 & 40 & 60 & 100 & 100 \\
\hline
\end{tabular}

Table 3: relative closeness of teacher to positive ideal solution

\begin{tabular}{c|c|c|c|c|c|c}
\hline close degree & 1 & 2 & 3 & 4 & 5 & 6 \\
\hline $\boldsymbol{d}^{+}$ & 0.3183 & 0.2381 & 0.2483 & 0.2703 & 0.1591 & 0.2798 \\
\hline $\boldsymbol{d}^{-}$ & 0.1057 & 0.1859 & 0.1757 & 0.1537 & 0.2649 & 01442 \\
\hline $\boldsymbol{C}^{+}$ & 0.2493 & 0.4384 & 0.4144 & 0.3625 & 0.6248 & 0.3401 \\
\hline close degree & 7 & 8 & 9 & 10 & 11 & 12 \\
\hline $\boldsymbol{d}^{+}$ & 0.1864 & 0.12849 & 0.1179 & 0.3124 & 0.1487 & 0.1272 \\
\hline $\boldsymbol{d}^{-}$ & 0.2376 & 0.2951 & 0.3061 & 0.1116 & 0.2753 & 0.2968 \\
\hline $\boldsymbol{C}^{+}$ & 0.5604 & 0.6960 & 0.7219 & 0.2632 & 0.6493 & 0.7000 \\
\hline
\end{tabular}

\section{4 epilogue}

In this paper, 14 evaluation indexes are constructed to evaluate the "double-teacher and three-ability type" of teachers. In the evaluation of TOPSIS method, the traditional TOPSIS weight method was improved, and the entropy weight-delphi method was used to determine the index weight, which was a combination of subjective and objective. It not only eliminates the influence of subjective one-sidedness of experts, but also eliminates the phenomenon of misjudgment caused by strong correlation between indicators, making the evaluation system more objective, scientific and reasonable. Through the case analysis, this method can provide the theoretical basis for the establishment of the teacher evaluation system, and provide the feasibility analysis for colleges and universities to build a "high-level" double-teacher team.

\section{Fund project}

Quality engineering project of Anhui province in 2018 (2018jyxm0620). Anhui Province University Discipline Specialty top talent academic funding project in 2018 (gxbjZD88).

\section{Author's introduction}

Wang Weixia, Female, Chongzuo, Guangxi, Master's degree, lecturer, Statistical analysis and research.

\section{Reference}

1. CHENG Yun-yan. The Design and Application of the Teacher Performance Appraisal Index System of "double-qualified" Teacher in Higher Vocational Colleges-Form the Perspective of Excellent Performance Management More and Fuzzy Analytic Hierarchy Process[J]. Journal of guangxi vocational and technical college, 2019, 12(02):88-93.

2. SHA Li. Research on the construction of "double-qualified" teachers in higher vocational colleges [D]. Shandong normal university, 2015.

3. ZhANG Wei-ping. On Construction Path of Double-professional Teachers in Higher Vocational Colleges from Perspective of Collaborative Innovation [J]. Analysis Research on higher education, 2014, 35(04): 56-59.

4. GE Zhong-xia. Countermeasure research on double teacher training in higher vocational education in anhui province [D]. Hefei university of technology, 2008.

5. ZHU Tian-tong, DING Jian-yong, ZHENG Xu. Comprehensive Decision-making Method of Power Grid Planning Scheme Based on Improved TOPSIS Method and Delphi - entropy Weight Comprehensive Weight Method [J]. Power system protection and control, 2018, 46(12): 91-99.

6. XU Yan-yan, SU Yang, YANG Mei-xia, MA li, LI Yan-min. Application of entropy weighted TOPSIS method combined with RSR method in compreh-e nsive evaluation of allocation of traditional Chinese 
medicine health resources [J]. Medical information, 2019,32(11): 130-133+137.

7. PENG Lin. Research on financial performance evaluation of baotou CJ company based on entropy weight TOPSIS -- a case study of 10 internal projects [J]. Value engineering,2019,38(17):39-42.

8. HUANG Yue-lian, MAO Yi-jun, KANG Feng-ying, LI Lin-bo. Application of weighted TOPSIS method to the performance evaluation of a hospital nursing unit [J]. Nursing research,2018,32(11):1761-1764.
9. MIAO Xiao-hui. Application of analytic hierarchy process in teaching performance evaluation of university teachers [J]. Contemporary educational practice and teaching research,2018(09):135-136.

10. YU You, ZHANG Guo-zheng, SHI Juan-rong. Evaluation of teaching quality of university teachers based on TOPSIS method [J]. Journal of langfang normal university (natural science edition), 2017,17(03):20-22+31. 